\title{
RESEARCH METHODS IN HUMAN RIGHTS: A HANDBOOK
}

\section{ISBN: 9781785367786 Price: $£ 150$ (Web £135)}

Whilst undoubtedly rooted legal scholarship, human rights, as a field, continues to undergo significant diversification in terms of the methodological techniques used to generate research. Research Methods in Human Rights: a Handbook provides researchers with insight into the various approaches that have emerged, along with the relative benefits and drawbacks of each. Edited by Bård A. Andreassen, Hans-Otto Sano and Siobhán McInerney-Lankford, the volume is available from Edward Elgar Publishing.

The editors have compiled an interesting and diverse set of contributions, drawing from the growing body of human rights research. When considered as a publication, the handbook serves to advocate for more a critical approach within the field, as well as serving to guide the researcher through the various methodological tools that have proliferated into human rights research. In light of the many challenges characterising the global environment, the requirement for interdisciplinary collaboration within the field of human rights should be increasingly clear; the publication is effective in providing the researcher with a critical discussion of the various approaches available, and accordingly its utility will be clear to researchers from both legal and social science backgrounds.

Several of chapters themselves provide the reader with clear and comprehensive instructions as to how to go about utilising various methodological techniques, as well 
as suggesting areas where they may be best applied. PhD and Masters Students may find the book to be particularly useful in developing effective methods for analysing human rights problems.

The book itself is divided into 2 major sections, with chapters 2 to 7 covering research methods that may be procured from within existing disciplines, and chapters 8 to 18 covering interdisciplinary methods. The first chapter represents an introduction, doing an effective job of outlining the historical developments in the field, in addition to outlining the reasons behind the lack of methodological development within human rights. The chapter goes on to clarify the conceptual blind spots and shortcomings that have characterised the field in the past as well as briefly summarising the contents of the book.

The second chapter by Martin Scheinin outlines the central importance of interpretation within human rights law, whist concurrently acknowledging the difficulties that exist in developing a sufficiently rigorous methodology. Whilst ultimately advocating for a more scientific approach to international legal scholarship, the chapter does not shy away from acknowledging the difficulties in accomplishing effective interpretation of human rights law. The chapter refers to treaties as well as customary law, discussing how interpretation relates to each. Considerations include the means of interpretation, the sources of international law, and the various barriers to a scientific method of interpretation. 
Chapter 3, authored by McInerney-Lankford provides a frank assessment of the methodological weaknesses prevailing in the otherwise solid body of human rights research. Much of the chapter approaches the lack of a critical approach inherent in much human rights scholarship, and the failure for researchers to be sufficiently critical of the norms foundational to human rights law. The chapter also consider the lack of emphasis on impact. The chapter suggests legal scholars approaching human rights should proceed with fewer assumptions and more readily consider the use of supplemental information and methods in order to better understand the impact and uptake of the norms they approach.

Chapter 4 introduces hermeneutics as a methodological approach to human rights, considering the interpretation of both legal text as well as human rights treaties The chapter provides a compelling description of how the approach of hermeneutics can provide a sufficiently critical means to engage with human rights problems.

Chapters 5 to 7 explore the relevance of a range of other disciplines and research methods to human rights. Chapter 5 for instance documents and discusses the exchange between economics and human rights scholarship. The chapter explains that there exists a solid basis for meaningful collaboration between the approaches, observing a convergence in terms of methods in recent published works; Anderson also notes how many methodological tools that are used in economics can be readily adapted to the analysis of human rights. In the same vein, Chapters 6 and 7 go on to 
discuss the relevance of historical and ethnographic techniques to the study of human rights respectively.

Part 2 deals with cross-disciplinary issues applicable to human rights research, including discussion of research ethics, the use of comparative methodologies and a range of issues surrounding conducting quantitative and qualitative research. In addition to identifying these key issues, part 2 provides a wealth of practical advice as to how to address methodological problems. The reviewer found Georges Ulrich's perspective on research ethics to represent a particularly salient contribution, perhaps being of interest to researchers conducting studies of an empirical or sensitive nature. Whilst many of the problems explored in the second part of this book may have long histories outside of human rights research, discussion of their relevance to this expanding area of scholarship represents a key contribution.

In summary, the volume sets out to "advance methodological awareness, competence and rigour, and therefore contribute to a greater understanding of the role of human rights in context". When considered in accordance with these aims, the book certainly achieves its goal, and will serve to not only inform new researchers, but also open up new areas for more established scholars. Whilst the price of the book is certainly a factor to consider, this book would represent an effective investment for researchers and institutions considering new approaches to human rights research.

Christopher J Morris

PhD researcher, Northumbria University 